\title{
Analisis Kebutuhan Traktor Berdasarkan Ketersediaan Air Pada Subak di Kabupaten Tabanan
}

\author{
Analysis of Tractor Needs Based on Water Availability in Tabanan Regency \\ I Gede Berliyantha Tikawa, I Wayan Tika *, Ida Bagus Putu Gunadnya \\ Program Studi Teknik Pertanian, Fakultas Teknologi Pertanian, Universitas Udayana, Badung, Bali, \\ Indonesia \\ *e-mail: wayantika@unud.ac.id
}

\begin{abstract}
Abstrak
Mengolah tanah dalam kegiatan pertanian memerlukan pengaturan kebutuhan traktor secara optimal. Jumlah traktor yang seharusnya dibutuhkan dengan luas lahan yang ada berdasarkan pada ketersediaan air di suatu subak dengan tujuan untuk memperoleh produktivitas hasil olah tanah yang optimal maka diperlukan traktor dengan ketersediaan air irigasi yang mengairi lahan untuk memperlancar pengolahan dan mengefisienkan tanah tersebut. Tujuan penelitian ini adalah untuk mengetahui banyaknya traktor yang diperlukan berdasarkan ketersediaan air dengan membandingkan traktor yang tersedia pada subak. Penelitian ini menggunakan pendekatan analisis kuantitatif melalui metode survey dengan mencari data primer yaitu pengukuran debit tersedia dibangunan bagi dan pengukuran dilahan. Hasil penelitian menunjukkan bahwa traktor yang dibutuhkan berdasarkan ketersediaan air di subak Kabupaten Tabanan yang ada di hulu, tengah dan hilir. Untuk sembilan subak yang ada di daerah hulu, traktor rotari yang diperlukan dengan rata-rata 6 traktor dapat mengolah lahan mencapai 87,3 ha atau 1 unit traktor dapat mengerjakan lahan dengan luas 14,6 ha dengan rata-rata konsumsi air untuk 1 unit traktor yaitu 27,16 lt/dt. Untuk sembilan subak yang ada di daerah tengah traktor yang diperlukan dengan rata-rata 5 traktor dapat mengolah lahan dengan luas 69 ha atau 1 unit traktor dapat mengerjakan lahan dengan luas 13,8 ha dengan rata-rata konsumsi air untuk 1 unit traktor yaitu 26,84 lt/dt. Sedangkan sembilan subak yang ada di daerah hilir traktor yang diperlukan dengan rata-rata 10 traktor dapat mengolah lahan dengan luas 114,5 ha atau 1 unit traktor dapat mengerjakan lahan dengan luas 11.8 ha dengan rata-rata konsumsi air untuk 1 unit traktor yaitu $12,1 \mathrm{lt} / \mathrm{dt}$.
\end{abstract}

Kata kunci: lahan, subak, tanah, traktor dan ketersediaan air

\begin{abstract}
Cultivating land in agricultural activities requires optimal regulation of tractor requirements. The number of tractors that should be needed with the available land area is based on the availability of water in a subak with the aim of obtaining optimal tillage productivity, so a tractor with the availability of irrigation water is needed to irrigate the land to facilitate processing and streamline the land. The purpose of this study is to determine the number of tractors needed based on water availability by comparing the tractors available on subak. This study uses a quantitative analysis approach through a survey method by finding primary data, namely the measurement of discharge available for building and land measurements. The results showed that the tractors needed were based on the availability of water in the subaks of Tabanan Regency in the upstream, middle and downstream areas. For the nine subaks in the upstream area, the required rotary tractor with an average of 6 tractors can cultivate land reaching 87.3 ha or 1 tractor unit can work on an area of 14.6 ha with an average water consumption for 1 unit of tractor which is $27.16 \mathrm{lt} / \mathrm{s}$. For the nine subaks in the central area of the tractor needed, with an average of 5 tractors, an area of 69 ha or 1 unit of tractor can work on an area of 13.8 ha with an average water consumption for 1 tractor unit, $26.84 \mathrm{lt} / \mathrm{s}$. While the nine subaks in the downstream area of the tractor needed with an average of 10 tractors can cultivate land with an area of 114.5 ha or 1 unit of tractor can work on land with an area of 11.8 ha with an average water consumption for 1 tractor unit that is $12.1 \mathrm{lt} / \mathrm{s}$.
\end{abstract}

Keywords: field, subak, soil, tractor and water availability

\section{PENDAHULUAN}

Kabupaten Tabanan sebagai lumbung beras di Bali tidak terlepas dari kelembagaan lokal yang telah lama melekat dimasyarakat yaitu sistem subak. Subak merupakan sistem kelembagaan masyarakat hukum adat yang bersifat sosio agraris, budaya, religius ekonomis, dan dinamis. Subak sangat berperan dalam menunjang pembangunan ekonomi di Provinsi Bali, khususnya pertanian. Penerapan teknologi di sektor pertanian itu sendiri salah satunya adalah penggunaan alat dan mesin pertanian. Penggunaan alat dan mesin pertanian dikembangkan agar pekerjaan lebih mudah dan efisien. Salah satu usaha untuk meningkatkan efisiensi dalam berusahatani adalah dengan pemakaian tenaga mekanis, seperti pengunaan traktor 
tangan untuk pengolahan tanah (Suyastiri, 2012). Pengolahan tanah berarti mengubah tanah pertanian dengan menggunakan suatu alat pertanian sedemikian rupa sehingga dapat diperoleh susunan tanah sebaikbaiknya, ditinjau dari struktur dan porositas tanah. Yang penting dalam pengolahan tanah adalah untuk menjamin keseimbangan antara air, udara, dan suhu di dalam tanah. Maka pengolahan tanah mutlak perlu guna menciptakan lingkungan yang cukup baik (Saraswati et al., 2007).

Tingkat penggunaan traktor dimasing-masing subak yang ada di Kabupaten Tabanan dari hulu hingga hilir ditentukan oleh ketersediaan air irigasi karena jika ketersediaan air irigasi banyak dengan lahan subak yang luas maka traktor yang diperlukan juga banyak, sedangkan jika air irigasi sedikit dengan lahan subak yang luasnya sedikit maka traktor yang diperlukan juga sedikit. Salah satu kasus adalah dimana banyaknya traktor yang tersedia disuatu subak semestinya dapat menyesuaikan dengan banyaknya traktor yang diperlukan, namun di lapangan ternyata traktor yang tersedia disuatu subak ada yang kurang dan juga berlebih menyebabkan traktor yang jumlahnya berlebih menjadi terbengkalai sehingga tidak sesuai dengan seberapa banyak traktor yang mestinya diperlukan. Maka dari itu perlu dilakukan perhitungan untuk mencari banyaknya traktor yang diperlukan berdasarkan ketersediaan air irigasi dan membandingkan dengan traktor yang tersedia pada subak bertujuan untuk mengetahui kondisi kecukupan traktor. Penggunaan traktor sangat dibutuhkan untuk meningkatkan efisiensi dalam kegiatan berusahatani (Soedjatmiko, 1999). Mengolah tanah dalam kegiatan pertanian diperlukan pengaturan kebutuhan traktor tangan dan ketersediaan air irigasi secara optimal yang dapat memberikan jumlah traktor tangan yang seharusnya dibutuhkan dengan luas lahan yang ada (Hardjosentono, 2000).

Ketersediaan air irigasi diperlukan untuk memenuhi kebutuhan air dilahan saat proses pengolahan tanah atau pembajakan berlangsung, sehingga pada saat traktor bekerja air irigasi yang mengairi lahan tercukupi agar traktor bekerja dengan baik, sehingga traktor dapat mengolah tanah dengan baik pada lahan tersebut (Fuadi et al., 2016). Untuk mengetahui jumlah traktor rotari yang dibutuhkan sesuai dengan ketersediaan air irigasi dengan luas lahan subak yang ada, maka tujuan dari penelitian ini untuk mengetahui traktor yang dibutuhkan berdasarkan ketersediaan air dengan luas luas lahan yang ada di subak Kabupaten Tabanan.

\section{METODE PENELITIAN}

\section{Tempat dan Waktu Penelitian}

Lokasi penelitian dilakukan pada subak yang berada di Kabupaten Tabanan sebanyak 27 subak yang berada di Daerah Alirah Sungai Yeh Ho dan Yeh Sungi, masing-masing subak dibagi 3 kriteria yaitu 9 subak di hulu, 9 subak di tengah dan 9 subak di hilir. Penelitian dilakasanakan pada musim tanam dari bulan Januari 2019 sampai Juli 2019.

\section{Alat dan Bahan Penelitian}

Alat dan bahan yang digunakan dalam penelitian ini adalah traktor rotari sebagai objek yang diteliti dalam kegiatan pengolahan tanah pertanian di Subak Kabupaten Tabanan, mistar atau penggaris digunakan untuk mengukur lebar ambang dan tinggi air mengalir pada petak lahan saat traktor bekerja, roll meter digunakan sebagai alat untuk mengukur luas lahan pertanian, kamera digital digunakan sebagai alat bantu dokumentasi, alat tulis diperlukan untuk mencatat data-data yang diperlukan.

\section{Pelaksanaan Penelitian}

Penelitian ini menggunakan pendekatan analisis kuantitatif dan metode wawancara. Wawancara dilakukan pada pekaseh masing-masing subak untuk mengetahui Luas lahan subak keseluruhan, nama saluran daerah irigasi yang mengairi subak tersebut, jumlah traktor dengan menggunakan bajak rotari atau traktor rotari yang tersedia di subak, lama persiapan lahan dan kapasitas olah 1 unit traktor. Pengukuran data primer untuk memperoleh debit air yang tersedia di bangunan bagi dengan cara mengukur lebar ambang dan tinggi air bangunan ukur pada intlet masing-masing subak daerah hulu, tengah dan hilir pada saat traktor bekerja dan pengukuran dilahan subak saat traktor bekerja.

\section{Pengukuran Debit Tersedia dan Pengukuran di Lahan}

Pengukuran debit tersedia dilakukan di bangunan bagi saluran inlet ke masing-masing subak yang berada di daerah hulu, tengah dan hilir dengan cara mengukur lebar ambang dan tinggi air di bangunan bagi saat traktor bekerja. Pengukuran dilahan saat traktor berkerja dilakukan dengan cara mengukur luas lima petak lahan yang dijadikan sampel mewakili lahan secara keseluruhan dalam 1 subak, mengukur kedalaman air pada petak yang dibajak, pengukuran debit $Q$ in atau air masuk $1 \mathrm{t} / \mathrm{dt}$ pada petak dan pengukuran debit $\mathrm{Q}$ out atau air keluar 1t/dt pada petak. Untuk titik pengukuran ada 9 yang tersebar dimasing - masing bangunan bagi di setiap subak dan titik pengukuran pada lahan terdapat pada saluran tersier yang ada pada lima petak lahan sawah mewakili 1 subak. 


\section{Analisis Kebutuhan Traktor}

Perhitungan kebutuhan traktor berdasarkan ketersediaan air dilakukan dengan contoh perhitungan sebagai berikut :

1. Luas petak lahan yaitu $=43,5$ are atau 0,435 ha Rata-rata konsumsi air pada pengolahan tanah untuk 1 traktor yaitu $=12,5 \mathrm{lt} / \mathrm{dt}$.

2. Dari data survei diperoleh kapasitas kerja 1 unit traktor $=0,60 /$ hari kerja, dimana 1 hari kerja $=6$ jam, dengan demikian untuk mengolah lahan seluas 0,435 ha (luas rata-rata petak lahan seperti pada Tabel 1)

$=\frac{\text { L. Petak lahan }}{\text { K. Kerja } 1 \text { unit traktor }} \times 1$ hari kerja $=\frac{0,435}{0,60} \times 6$ $\mathrm{jam}=4,35$ jam.

3. Dari Tabel 1 didapatkan, untuk mengolah lahan 0,435 ha konsumsi airnya yaitu $12,5 \mathrm{lt} / \mathrm{dt}$, dengan demikian untuk mengolah lahan sesuai dengan kapasitas kerja 1 unit traktor memerlukan air

$=\frac{\mathrm{K} . \text { Kerja } 1 \text { unit traktor }}{\mathrm{L} . \text { Petak lahan }} \times$ konsumsi air $=\frac{0,60}{0,435} \times$

$12,5 \mathrm{lt} / \mathrm{dt}=17,2 \mathrm{lt} / \mathrm{dt}$, dengan catatan debit air 17,2 $1 \mathrm{t} / \mathrm{dt}$ tersebut merupakan konsumsi air untuk proses pengolahan tanah oleh traktor rotari selama 6 jam dalam 1 hari kerja.

4. Dari survei di lapangan diperoleh debit air tersedia pada Subak Caguh (yang menjadi contoh perhitungan ini) $=229,6 \mathrm{lt} / \mathrm{dt}$ yang mengalir selama 24 jam dalam 1 hari.

5. Dari data pada butir 2, 3 dan 4, berdasarkan kebutuhan air saat olah tanah, maka diperoleh jumlah traktor maksimal yang bisa dilibatkan untuk mengolah tanan di Subak Caguh

$\underline{\text { Q. Tersedia } \mathrm{x} \text { air mengalir }: 1 \text { hari kerja }}=$ Konsumsi air 1 hari kerja

$229,6 \times 24: 6$ 17,2

6. Berdasarkan kesepakatan anggota dan pengurus Subak Caguh dan secara umum masa olah tanah subak yaitu 30 hari, jika 1 traktor dikerjakan berturut-turut selama 30 hari, maka lahan yang mampu diolah selama 30 hari tersebut $=0,60$ ha/hari x 30 hari $=18$ ha.

7. Luas Subak Caguh yaitu 180 ha, dengan demikian jumlah traktor yang diperlukan untuk mengolah semua lahan pada Subak Caguh berdasarkan hasil analisis butir 6 ,

$$
=\frac{\text { L. Lahan subak }}{\text { L. lahan diolah selama } 30 \text { hari }}=\frac{180 \text { ha }}{18 \text { ha }}=10
$$
traktor

8. Berdasarkan hasil analisis pada butir 3, 4, 5, 6 dan 7, maka dapat disimpulkan, berdasarkan kondisi ketersediaan air dan juga masa tenggang waktu olah tanah, maka jumlah traktor yang diperlukan Subak Caguh cukup 10 unit saja.

\section{HASIL DAN PEMBAHASAN}

\section{Traktor yang diperlukan Berdasarkan Ketersediaan Air pada Subak di Hulu}

Dari hasil perhitungan kebutuhan traktor berdasarkan ketersediaan air yang dilakukan untuk mengetahui banyaknya traktor rotari yang diperlukan untuk mengolah lahan subak di daerah hulu yang dilaksanakan pada musim tanam bulan Januari-Juni, diperoleh rata-rata 6 traktor rotari dapat mengolah lahan mencapai 87,3 ha atau 1 unit traktor dapat mengerjakan lahan dengan luas 14,6 ha dengan ratarata konsumsi air untuk 1 unit traktor yaitu 27,16 lt/dt dan rata-rata debit air mengalir ke lahan yaitu 1,87 lt/dt/ha. Untuk lebih jelasnya dapat dilihat pada Tabel 1.

Tabel 1, menunjukan bahwa dari sembilan subak yang ada di daerah hulu, traktor yang diperlukan paling banyak ada pada dua subak yaitu Subak Aya Pemanis dan Subak Aya Gluntung sebanyak 9 traktor rotari, disebabkan ketersedian air yang besar dan luas lahan yang dimiliki lebih luas dari subak lainnya yang ada di hulu, sedangkan ada dua subak dengan ketersediaan air lebih besar dibandingkan dengan Subak Aya Pemanis dan Subak Aya Gluntung yaitu Subak Palian dan Subak Pama, tetapi luas lahan yang dimiliki kedua subak tersebut lebih sedikit dibandingkan dengan Subak Aya Pemanis dan Subak Aya Gluntung, sehingga traktor yang diperlukan pada Subak Palian dan Subak Pama lebih sedikit jumlahnya. Untuk traktor yang diperlukan paling sedikit ada pada Subak Bangan yaitu 4 traktor rotari disebabkan ketersediaan air dan luas lahan pada subak tersebut lebih sedikit dari subak lainnya yang ada di hulu. Menurut Suheiti (2016), besar kecilnya debit air pada saluran irigasi dan luas lahan dapat mempengaruhi kapasitas kerja atau banyaknya traktor yang diperlukan saat mengolah tanah pada lahan persawahan. 
Tabel 1. Traktor yang diperlukan berdasarkan ketersediaan air pada subak yang terletak di hulu

\begin{tabular}{|c|c|c|c|c|c|}
\hline \multicolumn{6}{|c|}{ Hulu } \\
\hline $\begin{array}{l}\text { Nama Subak \& } \\
\text { wilayah subak }\end{array}$ & $\begin{array}{c}\text { Luas } \\
\text { Lahan } \\
\text { Subak } \\
\text { (ha) }\end{array}$ & $\begin{array}{c}\text { Luas } 5 \\
\text { Sampel } \\
\text { Petak } \\
\text { (are) }\end{array}$ & $\begin{array}{l}\text { Q Tersedia } \\
\text { Pada Subak } \\
\text { (lt/dt) }\end{array}$ & $\begin{array}{l}\text { Q Mengairi } 5 \\
\text { Sampel Petak } \\
\text { (lt/dt) }\end{array}$ & $\begin{array}{c}\text { Traktor } \\
\text { Rotari yang } \\
\text { Diperlukan } \\
\text { (unit/ha) }\end{array}$ \\
\hline $\begin{array}{l}\text { Subak Palian } \\
\text { (Desa Perean) }\end{array}$ & 88.9 & 17.5 & 233.40 & 11.9 & 7 \\
\hline $\begin{array}{l}\text { Subak Bangan } \\
\text { (Desa Perean) }\end{array}$ & 40.0 & 17.9 & 35.32 & 7.3 & 3 \\
\hline $\begin{array}{l}\text { Subak Pama } \\
\text { (Desa Perean) }\end{array}$ & 88.0 & 11.8 & 233.40 & 11.8 & 6 \\
\hline $\begin{array}{l}\text { Subak Babahan } \\
\text { (Desa Bolangan) }\end{array}$ & 90.0 & 16.3 & 152.18 & 10.3 & 7 \\
\hline $\begin{array}{l}\text { Subak Jambelangu } \\
\text { (Desa Bolangan) }\end{array}$ & 50.0 & 13.9 & 95.24 & 10.0 & 5 \\
\hline $\begin{array}{l}\text { Subak Belangkunang } \\
\text { (Desa Dadia) }\end{array}$ & 85.0 & 12.4 & 72.05 & 10.9 & 6 \\
\hline $\begin{array}{l}\text { Subak Aya Sunantaya } \\
\text { (Desa Sunantaya) }\end{array}$ & 57.8 & 15.3 & 28.27 & 10.3 & 5 \\
\hline $\begin{array}{l}\text { Subak Aya Pemanis } \\
\text { (Desa Pemanis) }\end{array}$ & 149.0 & 18.6 & 211.06 & 11.7 & 9 \\
\hline $\begin{array}{l}\text { Subak Aya Gluntung } \\
\text { (Desa Gluntung) }\end{array}$ & 145.0 & 14.5 & 211.06 & 13.1 & 9 \\
\hline Rata-rata & 88.1 & 15.3 & 163.60 & 10.8 & 6 \\
\hline \multicolumn{4}{|c|}{ Rata-rata kapasitas kerja 1 unit traktor (ha) } & 14.6 & \\
\hline \multicolumn{4}{|c|}{ Rata-rata konsumsi air Untuk 1 unit traktor (lt/dt) } & 27.16 & \\
\hline \multicolumn{4}{|c|}{ Rata-rata debit air mengalir ke lahan (lt/dt/ha) } & 1.86 & \\
\hline
\end{tabular}

Keterangan : $\mathrm{Q}=$ debit air irigasi, masa olah tanah $=21-30$ hari, kapasitas kerja $=0,45-0,55$ ha

Traktor yang diperlukan Berdasarkan Ketersediaan Air pada Subak di Tengah.

Traktor yang diperlukan berdasarkan ketersediaan air pada subak yang terletak di tengah saat pengolahan tanah yang dilaksanakan pada musim tanam bulan Januari-Juni, diperoleh rata-rata 5 traktor rotari dapat mengolah lahan dengan luas 69 ha atau 1 unit traktor dapat mengerjakan lahan dengan luas 13,8 ha dengan rata-rata konsumsi air untuk 1 unit traktor yaitu 26,84 $1 \mathrm{t} / \mathrm{dt}$ dan rata-rata debit air mengalir ke lahan yaitu $1,94 \mathrm{lt} / \mathrm{dt} / \mathrm{ha}$. Untuk lebih jelasnya ditunjukkan pada Tabel 2.

Tabel 2, menunjukan bahwa dari sembilan subak yang ada di daerah tengah, traktor yang diperlukan paling banyak ada pada dua subak, Subak Caguh 10 traktor rotari dan Subak Guama sebanyak 12 traktor rotari, disebabkan ketersedian air yang besar dan lahan yang dimiliki lebih luas dari subak lainnya yang ada di tengah, namun ada dua subak dengan ketersediaan air pada subak-subak tersebut sangat besar yaitu pada Subak Sambian dan Subak Kesiut tetapi luas lahan yang dimiliki kedua subak tersebut lebih sedikit dibandingkan dengan Subak Caguh dan Subak Guama sehingga traktor yang diperlukan pada Subak Sambian dan Subak Kesiut lebih sedikit jumlahnya. Mengolah tanah persawahan yang luas di lahan datar dengan tujuan untuk memeperoleh produktivitas tanah yang optimal, maka diperlukan traktor dengan menggunakan bajak rotari untuk memperlancar pengolahan dan mengefisienkan tanah tersebut (Yunus et al., 2017). Terdapat empat subak untuk traktor yang diperlukan dengan jumlah paling sedikit yaitu 2 traktor yang terdapat pada Subak Jangkan, Subak Kerobokan, Subak Pandan dan Subak Aya 3 traktor rotari yang disebabkan ketersediaan air sangat sedikit dan luas lahan keempat subak tersebut sudah berkurang akibat alih fungsi lahan yang banyak didirikan bangunan menjadi pemukiman penduduk. Irawan dan Friyatno (2002), menyatakan bahwa pada tingkatan mikro proses alih fungsi lahan pertanian dapat dilakukan oleh petani sendiri atau dilakukan oleh pihak lain. 
Tabel 2. Traktor yang diperlukan berdasarkan ketersediaan air pada subak yang terletak di tengah

\begin{tabular}{|c|c|c|c|c|c|}
\hline \multicolumn{6}{|c|}{ Tengah } \\
\hline $\begin{array}{l}\text { Nama Subak \& } \\
\text { wilayah subak }\end{array}$ & $\begin{array}{c}\text { Luas } \\
\text { Lahan } \\
\text { (ha) }\end{array}$ & $\begin{array}{c}\text { Luas } 5 \\
\text { Sampel } \\
\text { Petak } \\
\text { (are) }\end{array}$ & $\begin{array}{l}\text { Q Tersedia } \\
\text { Pada Subak } \\
\text { (It/dt) }\end{array}$ & $\begin{array}{c}\text { Q Mengairi } \\
5 \text { Sampel } \\
\text { Petak (lt/dt) }\end{array}$ & $\begin{array}{c}\text { Traktor } \\
\text { Rotari yang } \\
\text { diperlukan } \\
\text { (unit/ha) }\end{array}$ \\
\hline $\begin{array}{l}\text { Subak Sambian } \\
\text { (Desa Timpag) }\end{array}$ & 67.0 & 44.6 & 223.23 & 11.1 & 6 \\
\hline $\begin{array}{l}\text { Subak Kesiut } \\
\text { (Desa Kesiut) }\end{array}$ & 47.0 & 56.3 & 272.02 & 13.1 & 5 \\
\hline $\begin{array}{l}\text { Subak Caguh } \\
\text { (Desa Sarasidi) }\end{array}$ & 180.0 & 43.5 & 229.65 & 12.5 & 10 \\
\hline $\begin{array}{l}\text { Subak Jangkan } \\
\text { (Desa Abian Tuung) }\end{array}$ & 20.0 & 25.0 & 40.61 & 9.2 & 2 \\
\hline $\begin{array}{l}\text { Subak Kerobokan } \\
\text { (Desa Abian Tuung) }\end{array}$ & 20.0 & 19.0 & 40.61 & 9.3 & 2 \\
\hline $\begin{array}{l}\text { Subak Pandan } \\
\text { (Desa Jebaud) }\end{array}$ & 19.0 & 22.6 & 40.27 & 9.1 & 2 \\
\hline $\begin{array}{l}\text { Subak Aya } \\
\text { (Desa Jebaud) }\end{array}$ & 24.0 & 17.2 & 41.15 & 9.4 & 3 \\
\hline $\begin{array}{l}\text { Subak Guama } \\
\text { (Desa Kekeran) }\end{array}$ & 187.0 & 30.9 & 228.58 & 11.7 & 12 \\
\hline $\begin{array}{l}\text { Subak Selanbawak } \\
\text { (Desa Selanbawak) }\end{array}$ & 58.0 & 21.8 & 92.07 & 10.4 & 5 \\
\hline Rata-rata & 69.0 & 31.2 & 134.2 & 10.6 & 5 \\
\hline \multicolumn{4}{|c|}{ Rata-rata kapasitas kerja 1 unit traktor (ha) } & 13.8 & \\
\hline \multicolumn{4}{|c|}{ Rata-rata konsumsi air Untuk 1 unit traktor (1t/dt) } & 26.84 & \\
\hline \multicolumn{4}{|c|}{ Rata-rata debit air mengalir ke lahan (lt/dt/ha) } & 1.94 & \\
\hline
\end{tabular}

Keterangan : $\mathrm{Q}=$ debit air irigasi, masa olah tanah $=21-30$ hari, kapasitas kerja $=0,45-0,60$ ha

\section{Traktor yang diperlukan Berdasarkan Ketersediaan Air pada Subak di Hilir.}

Traktor yang diperlukan berdasarkan ketersediaan air pada subak yang terletak di hilir saat kegiatan pengolahan tanah yang dilaksanakan pada musim tanam bulan Januari-Juni, diperoleh rata-rata 10 traktor dapat mengolah lahan dengan luas 114,5 ha atau 1 unit traktor dapat mengerjakan lahan dengan luas 11.8 ha dengan rata-rata konsumsi air untuk 1 unit traktor yaitu $12,1 \mathrm{lt} / \mathrm{dt}$ dan rata-rata debit air mengalir ke lahan yaitu 1,06 lt/dt/ha. Untuk lebih jelasnya dapat dilihat pada Tabel 3 .

Tabel 3, menunjukan bahwa dari sembilan subak yang ada di hilir, traktor yang diperlukan paling banyak ada pada Subak Sungsang yaitu 17 traktor rotari, disebabkan ketersedian air yang besar yaitu
231,89 lt/dt dan luas lahan yang dimiliki subak tersebut seluas 224,12 Ha dengan kapasitas olah 1 unit traktor mencapai $0,55 \mathrm{Ha}$, maka diperlukan 17 traktor rotari untuk mengolah tanah pada subak tersebut. Menurut penelitian yang dilakukan suheiti (2016), luas lahan sawah irigasi dan non irigasi Jawa Timur dalam satu kali musim tanam adalah 1.177.160 Ha, jika kapasitas kerja maksimal traktor bisa mencapai $30 \mathrm{Ha}$ /unit, maka jumlah traktor yang dibutuhkan 39.239 unit traktor/musimnya. Untuk traktor yang diperlukan paling sedikit ada pada Subak Bangan yaitu 4 traktor rotari disebabkan ketersediaan air yang sedikit yaitu 36,71 lt/dt dan luas lahan pada subak tersebut lebih sedikit dari subak lainnya yang ada di hilir yaitu seluas $66 \mathrm{Ha}$ dengan kapasitas olah 1 unit traktor mencapai $0,55 \mathrm{Ha}$. 
Tabel 3. Traktor yang diperlukan berdasarkan ketersediaan air pada subak yang terletak di hilir

\begin{tabular}{|c|c|c|c|c|c|}
\hline \multicolumn{6}{|c|}{ Hilir } \\
\hline $\begin{array}{c}\text { Nama Subak \& } \\
\text { wilayah subak }\end{array}$ & $\begin{array}{c}\text { Luas } \\
\text { Lahan } \\
\text { (ha) }\end{array}$ & $\begin{array}{c}\text { Luas } 5 \\
\text { Sampel } \\
\text { Petak } \\
\text { (are) }\end{array}$ & $\begin{array}{c}\text { Q Tersedia } \\
\text { Pada } \\
\text { Subak } \\
\text { (lt } / \mathbf{d t} \text { ) }\end{array}$ & $\begin{array}{c}\text { Q Mengairi } \\
5 \text { Sampel } \\
\text { Petak (lt/dt) }\end{array}$ & $\begin{array}{c}\text { Traktor } \\
\text { Rotari yang } \\
\text { Diperlukan } \\
\text { (unit/ha) }\end{array}$ \\
\hline $\begin{array}{l}\text { Subak Gadon I } \\
\text { (Desa Pandak) }\end{array}$ & 135.0 & 20.1 & 191.94 & 10.6 & 10 \\
\hline $\begin{array}{l}\text { Subak Gadon II } \\
\text { (Desa Beraban) }\end{array}$ & 154.38 & 17.7 & 154.38 & 9.2 & 13 \\
\hline $\begin{array}{l}\text { Subak Blumbang } \\
\text { (Desa Blumbang) }\end{array}$ & 174.0 & 27.5 & 166.45 & 10.2 & 13 \\
\hline $\begin{array}{l}\text { Subak Sungsang } \\
\text { (Desa Tibubiu) }\end{array}$ & 224.12 & 35.6 & 231.89 & 12.2 & 17 \\
\hline $\begin{array}{l}\text { Subak Aseman IV } \\
\text { (Desa Megati) }\end{array}$ & 137.0 & 11.7 & 100.93 & 9.6 & 11 \\
\hline $\begin{array}{l}\text { Subak Aseman V } \\
\text { (Desa Megati) }\end{array}$ & 87.0 & 22.2 & 114.78 & 9.3 & 7 \\
\hline $\begin{array}{l}\text { Subak Aseman II } \\
\text { (Desa Megati) }\end{array}$ & 85.0 & 18.3 & 57.60 & 8.9 & 5 \\
\hline $\begin{array}{l}\text { Subak Gadungan } \\
\text { (Desa Gadungan) }\end{array}$ & 66.0 & 19.9 & 36.71 & 7.0 & 4 \\
\hline $\begin{array}{l}\text { Subak Baleagung Kelod } \\
\text { (Desa Gadungan) }\end{array}$ & 125.0 & 20.3 & 37.82 & 7.6 & 8 \\
\hline Rata-rata & 114.5 & 21.4 & 121.38 & 9.4 & 10 \\
\hline \multicolumn{4}{|c|}{ Rata-rata kapasitas kerja 1 unit traktor (ha) } & 11.8 & \\
\hline \multicolumn{4}{|c|}{ Rata-rata konsumsi air Untuk 1 unit traktor (lt/dt) } & 12.1 & \\
\hline \multicolumn{4}{|c|}{ Rata-rata debit air mengalir ke lahan (lt/dt/ha) } & 1.06 & \\
\hline
\end{tabular}

Keterangan : $\mathrm{Q}=$ debit air irigasi, masa olah tanah $=21-30$ hari, kapasitas kerja $=0,45-060$ ha

Kondisi Kecukupan Traktor yang diperlukan dan Traktor yang Tersedia pada Subak di Hulu.

Kondisi kecukupan jumlah traktor yang diperlukan dan jumlah traktor yang tersedia pada subak di hulu dapat dilihat pada Tabel 4.

Tabel 4 menunjukan, berdasarkan sembilan subak yang ada di hulu, ada enam subak untuk traktor yang dapat dikategorikan cukup terdapat pada Subak Palian, Subak Bangan, Subak Pama, Subak Aya Sunantaya, Subak Aya Pemanis dan Subak Aya Gluntung, dikarenakan pada subak-subak tersebut traktor yang di perlukan dan traktor yang tersedia sudah sesuai jumlahnya. Untuk traktor yang dikategorikan kurang terdapat pada tiga subak yaitu Subak Babahan, Subak Jambelangu dan Subak Belangkunang, dikarenakan traktor rotari yang tersedia sedikit jumlahnya, disebabkan kontur lahan ketiga subak tersebut lebih banyak terasering, maka kebanyakan petani pada subak-subak tersebut cenderung memilih menggunakan traktor berukuran kecil atau orong-orong bahkan dimiliki secara pribadi oleh petani, sedangkan hanya ada beberapa traktor rotari yang memang tersedia pada subak berkat bantuan dari pemerintah dan juga dimiliki pribadi oleh beberapa petani dengan jumlah yang sedikit. Zakaria (2009), menyatakan terasering merupakan metode konservasi lahan secara mekanis yang dibuat untuk memperpendek panjang memperkecil kemiringan lereng, dengan luas petakan yang sempit alat pengolahan tanah atau traktor yang digunakan berukuran kecil menyesuaikan ukuran petak lahan agar lebih efisien. Tanah bergerak perlahan- lahan, infiltarsi air kurang dan air tersedia kurang bagi aktivitas kimia dan biologi, perlakuan pengenangan dan pengeringan lahan pada lahan sawah menyebabkan terjadinya perubahan sifat tanah (Lubis, 2017). 
Tabel 4. Traktor yang diperlukan dan traktor yang tersedia pada subak yang terletak di hulu

\begin{tabular}{lcccc}
\hline \multicolumn{1}{c}{ Nama Subak \& } & Hulu & & & \\
wilayah subak & $\begin{array}{c}\text { Luas } \\
\text { Lahan } \\
\text { (ha) }\end{array}$ & $\begin{array}{c}\text { T. Rotari } \\
\text { diperlukan } \\
\text { (unit) }\end{array}$ & $\begin{array}{c}\text { T. Rotari } \\
\text { Tersedia } \\
\text { (unit) }\end{array}$ & Keterangan \\
Subak Palian (Desa Perean) & 88.9 & 7 & 7 & Cukup \\
Subak Bangan (Desa Perean) & 40.0 & 3 & 3 & Cukup \\
Subak Pama (Desa Perean) & 88.0 & 6 & 6 & Cukup \\
Subak Babahan (Desa Bolangan) & 90.0 & 7 & 5 & Kurang \\
Subak Jambelangu (Desa Bolangan) & 50.0 & 5 & 4 & Kurang \\
Subak Belangkunang (Desa Dadia) & 85.0 & 6 & 4 & Kurang \\
Subak Aya Sunantaya (Desa Sunantaya) & 57.8 & 5 & 5 & Cukup \\
Subak Aya Pemanis (Desa Pemanis) & 149.0 & 9 & 9 & Cukup \\
Subak Aya Gluntung (Desa Gluntung) & 145.0 & 9 & 9 & Cukup \\
\multicolumn{1}{c}{ Rata-rata } & 88.1 & 6 & 6 & \\
\hline
\end{tabular}

\section{Keterangan : T. Rotari $=$ traktor rotari}

\section{Kondisi Kecukupan Traktor yang diperlukan dan Traktor yang Tersedia pada Subak di Tengah.}

Kondisi kecukupan traktor yang diperlukan dan traktor yang tersedia pada subak di tengah dapat dilihat pada Tabel 5 .

Tabel 5 menunjukan, berdasarkan sembilan subak yang ada di tengah, terdapat lima subak untuk traktor yang dapat dikategorikan lebih yaitu Subak Sambian,
Subak Kesiut, Subak Jangkan, Subak Pandan dan Subak Aya, dikarenakan jumlah traktor rotari yang tersedia pada subak melebihi jumlah traktor yang diperlukan, disebabkan traktor rotari yang tersedia pada subak-subak tersebut selain memang ada pada subak berkat bantuan dari pemerintah untuk dipakai bersama oleh anggota subak, petani atau anggota subak juga memiliki traktor rotari secara pribadi.

Tabel 5. Traktor yang di perlukan dan traktor yang tersedia pada subak yang terletak di tengah

\begin{tabular}{|c|c|c|c|c|}
\hline \multicolumn{5}{|c|}{ Tengah } \\
\hline $\begin{array}{l}\text { Nama Subak \& } \\
\text { wilayah subak }\end{array}$ & $\begin{array}{c}\text { Luas } \\
\text { Lahan } \\
\text { (ha) }\end{array}$ & $\begin{array}{l}\text { T. Rotari } \\
\text { diperlukan } \\
\text { (unit) }\end{array}$ & $\begin{array}{l}\text { T. Rotari } \\
\text { Tersedia } \\
\text { (unit) }\end{array}$ & Keterangan \\
\hline Subak Sambian (Desa Timpag) & 67 & 6 & 8 & Lebih \\
\hline Subak Kesiut (Desa Kesiut) & 47 & 5 & 7 & Lebih \\
\hline Subak Caguh (Desa Sarasidi) & 180 & 10 & 7 & Kurang \\
\hline Subak Jangkan (Desa Abian Tuung) & 20 & 2 & 3 & Lebih \\
\hline Subak Kerobokan (Desa Abian Tuung) & 20 & 2 & 2 & Cukup \\
\hline Subak Pandan (Desa Jebaud) & 19 & 2 & 3 & Lebih \\
\hline Subak Aya (Desa Jebaud) & 24 & 3 & 4 & Lebih \\
\hline Subak Guama (Desa Kekeran) & 187 & 12 & 9 & Kurang \\
\hline Subak Selanbawak (Desa Selanbawak) & 58 & 5 & 4 & Kurang \\
\hline Rata-rata & 69 & 5 & 5 & \\
\hline
\end{tabular}

\section{Keterangan : T. Rotari $=$ traktor rotari}

Untuk traktor yang dikategorikan kurang terdapat pada tiga subak yaitu Subak Caguh, Subak Guama, dan Subak Selanbawak, dikarenakan traktor yang tersedia sedikit jumlahnya, disebabkan ketiga subak tersebut petani pemilik lahan atau anggota subak yang dulunya memiliki traktor rotari secara pribadi kini traktor tersebut sudah rusak dan tidak bisa dipakai sehingga petani memilih menyewa traktor dan juga 
operatornya dikarenakan biaya yang dikeluarkan lebih murah daripada membeli traktor dengan kondisi baru. Traktor yang dapat dikatagorikan cukup terdapat pada Subak Kerobokan, dikarenakan pada subak tersebut traktor yang diperlukan dan traktor yang tersedia sudah sesuai jumlahnya. Menurut
Bachrein et al (2009) umumnya petani menyewa traktor kepada pemilik dengan sistem pembayaran upah sewa adalah dibayar setelah selesai pengolahan tanah atau dibayar 1/2 minggu setelah pengolahan tanah selesai.

Tabel 6. Traktor yang diperlukan dan traktor yang tersedia pada subak yang terletak di hilir

\begin{tabular}{|c|c|c|c|c|}
\hline \multicolumn{5}{|c|}{ Hilir } \\
\hline $\begin{array}{c}\text { Nama Subak \& } \\
\text { wilayah subak }\end{array}$ & $\begin{array}{l}\text { Luas } \\
\text { Lahan } \\
\text { (ha) }\end{array}$ & $\begin{array}{l}\text { T. Rotari } \\
\text { diperlukan } \\
\text { (unit) }\end{array}$ & $\begin{array}{l}\text { T. Rotari } \\
\text { Tersedia } \\
\text { (unit) }\end{array}$ & Keterangan \\
\hline Subak Gadon I (Desa Pandak) & 135.0 & 10 & 12 & Lebih \\
\hline Subak Gadon II (Desa Beraban) & 154.38 & 13 & 13 & Cukup \\
\hline Subak Blumbang (Desa Blumbang) & 174.0 & 13 & 13 & Cukup \\
\hline Subak Sungsang (Desa Tibubiu) & 224.12 & 17 & 23 & Lebih \\
\hline Subak Aseman IV (Desa Megati) & 137.0 & 11 & 11 & Cukup \\
\hline Subak Aseman V (Desa Megati) & 87.0 & 7 & 7 & Cukup \\
\hline Subak Aseman II (Desa Megati) & 85.0 & 5 & 5 & Cukup \\
\hline Subak Gadungan (Desa Gadungan) & 66.0 & 4 & 8 & Lebih \\
\hline Subak Baleagung Kelod (Desa Gadungan) & 125.0 & 8 & 10 & Lebih \\
\hline Rata-rata & 114.5 & 10 & 11 & \\
\hline
\end{tabular}

Keterangan $:$ T. Rotari $=$ traktor rotari

Kondisi Kecukupan Traktor yang diperlukan dan Traktor yang Tersedia pada Subak di Hilir.

Kondisi kecukupan traktor yang diperlukan dan traktor yang tersedia pada subak di hilir dapat dilihat pada Tabel 6. Tabel 6 menunjukan, berdasarkan sembilan subak yang ada di hilir, ada empat subak untuk traktor dapat dikategorikan lebih terdapat pada Subak Gadon I, Subak Sungsang, Subak Gadungan dan Subak Baleagung Kelod, dikarenakan jumlah traktor yang tersedia melebihi jumlah traktor yang diperlukan, sama seperti beberapa subak yang ada di daerah tengah, traktor rotari yang terdapat pada subak-subak tersebut sebagian besar dimiliki oleh petani pribadi dengan jumlah yang banyak. Untuk traktor yang dikatagorikan cukup terdapat pada lima subak yaitu Subak Gadon II, Subak Blumbang, Subak Aseman IV, Subak Aseman V dan Subak Aseman II dikarenakan pada subak-subak tersebut traktor yang diperlukan dan traktor yang tersedia jumlahnya sudah sesuai. Keberhasilan pemanfaatan traktor secara luas di tingkat petani sangat dipengaruhi dan berinteraksi dengan faktor-faktor lainnya, seperti aspek teknis, usaha tani/budidaya, sumber daya, permodalan, sosial, lingkungan dan kebijakan pemerintah. Sistem juga dapat terdiri atas beberapa sub-sistem, yaitu penelitian dan pengembangan, penyuluhan, dan pengguna (petani). Semua subsistem tersebut terkait satu sama lain dalam suatu jejaring kerjasama dengan mekanisme kerja yang terarah dan terkoordinasi dalam suatu program/kegiatan yang terpadu, konsisten dan berkelanjutan (Bachrein et al., 2009).

\section{KESIMPULAN DAN SARAN}

\section{Kesimpulan}

Berdasarkan hasil penelitian dapat disimpulkan bahwa:

Di daerah hulu untuk ketersediaan air 211,06 lt/dt/ha diperlukan 9 traktor rotari untuk mengolah tanah pada lahan subak, di daerah tengah untuk ketersediaan air 40,61 lt/dt/ha diperlukan 2 traktor rotari dan di daerah hilir untuk ketersediaan air 231,89 1t/dt/ha diperlukan 17 traktor rotari. Maka jika ketersediaan air irigasi banyak dengan luas lahan yang besar, traktor yang diperlukan juga banyak dan jika ketersediaan air irigasi sedikit dengan luas lahan yang sedikit, maka traktor yang diperlukan juga sedikit.

Traktor yang dapat dikategorikan cukup untuk subak di hulu terdapat pada enam subak, traktor yang dikategorikan kurang terdapat pada tiga subak. Traktor yang dapat dikategorikan lebih untuk subak di tengah terdapat pada lima subak, untuk traktor yang dikategorikan kurang terdapat pada tiga subak, traktor yang dapat dikategorikan cukup terdapat pada satu subak. Di hilir traktor yang dapat dikategorikan 
lebih terdapat pada empat subak, untuk traktor yang dikatagorikan cukup terdapat pada lima subak.

\section{Saran}

Berdasarkan hasil penelitian ini disarankan:

Pentingnya ketersediaan air irigasi pada saat traktor bekerja karena jika tidak ada air yang mengairi lahan, kerja traktor menjadi terhambat atau tidak maksimal, maka sistem pembagian air pada suatu subak saat pengolahan tanah berlangsung perlu dibenahi agar pembagian air menjadi merata dan jumlah traktor yang digunakan menjadi sesuai dengan ketersediaan air dan luas lahan.

Perlu adanya sosialisasi pengetahuan tentang perawatan dan penggunaan traktor agar sesuai dengan keperluan untuk pengolahan tanah, supaya traktortraktor yang tersedia pada subak semua terpakai dan berfungsi dengan baik, sehingga tidak ada traktor yang tidak digunakan dan menjadi terbengkalai.

\section{DAFTAR PUSTAKA}

Aisyah, S. (2015). Analisis Kebutuhan dan Pengelolaan Traktor Tangan pada Kegiatan Pengolahan Tanah Pertanian di Desa Sumber Kalong Kecamatan Kalisat.

Bachrein, S., Ruswandi, A., dan Subarna, T. (2009). Penggunaan Traktor Roda Dua pada Lahan Padi Sawah di Jawa Barat. Agrikultura, 20(3).

Fuadi, N. A., Purwanto, M. Y. J., dan Tarigan, S. D. (2016). Kajian Kebutuhan Air dan Produktivitas Air Padi Sawah dengan Sistem Pemberian Air secara Sri dan Konvensional Menggunakan Irigasi Pipa. Jurnal Irigasi, 11(1), 23-32.
Hardjosentono, M, 2010. Mesin- Mesin Pertanian. Pusat Pendidikan Dan Latihan Pertanian. Jakarta

Irawan, B., dan Friyatno, S. 2002. Dampak Konversi Lahan Sawah di Jawa terhadap Produksi Beras dan Kebijakan Pengendaliannya. SOCA (Socio-Economic of Agriculturre And Agribusiness). Bogor.

Lubis, N. M. A. I., dan Nasution, Z. (2017). Klasifikasi Tanah Lahan Sawah Terasering di Desa Huta Hotang Kecamatan Onan Runggu Berdasarkan Toposekuen. Jurnal Online Agroekoteknologi, 5(4), 764-772.

Soedjatmiko. 1999. Masalah Penggunaan Traktor Dalam Budidaya Pertanian di Indonesia. Fakultas Teknologi Pertanian. Institut Pertanian Bogor. Bogor

Saraswati, R., dan Husen, E. (2007). Prospek Penggunaan Pupuk Hayati Pada Sawah Bukaan Baru. di Dalam: Prosiding Tanah Sawah Bukaan Baru. Balai Besar Litbang Sumberdaya Lahan Pertanian, BBLSLP, Bogor. Hlm, 151-174.

Suheiti, K. (2016). Peran Traktor Roda Dua dalam Gerakan Percepatan Tanam Padi di Jawa Timur: Sebuah Review.

Suyastiri, Y. P. N. M. (2012). Pemberdayaan Subak Melalui "Green Tourism" Mendukung Keberlanjutan Pembangunan Pertanian Di Bali. SEPA, 8(2), 51-182

Yunus, L., Iswandi, M., dan Hasan, I. (2017). Optimalisasi Kebutuhan Traktor Untuk Pengolahan Tanah Sawah Di Kecamatan Wundulako Kabupaten Kolaka. Jurnal Sosio Agribisnis, 1(1).

Zakaria, Z. 2009. Analisis Kestabilan Lereng Tanah. Laboratorium Geologi Fakultas Teknik Geologi Universitas Padjadjaran. Bandung. 